\title{
Maxillary Second Molar with Single Root and Single Canal-Case Report
}

\author{
Nexhmije Ajeti ${ }^{1}$ Violeta Vula1, Sonja Apostolska², Teuta Pustina ${ }^{3 *}$, Tringa Kelmendi' \\ Lindihana Emini4, Shefqet Mrasori' ${ }^{1}$, Resmije Ademi ${ }^{5}$ \\ ${ }^{1}$ Department of Endodontic and Dental Pathology, Dental Branch, Medical Faculty, University of Prishtina, \\ Prishtina, Kosovo \\ ${ }^{2}$ Department of Endodontic and Dental Pathology, Dental Faculty, University of Skopje, Skopje, Macedonia \\ ${ }^{3}$ Department of Prosthetic Dentistry, Dental Branch, Medical Faculty, University of Prishtina, Prishtina, Kosovo \\ ${ }^{4}$ Department of Endodontic and Dental Pathology, Dental Branch, Medical Faculty, University of Tetovo, \\ Tetovo, Macedonia \\ ${ }^{5}$ Department of Oral Surgery, Dental Branch, Medical Faculty, University of Prishtina, Prishtina, Kosovo \\ Email: nexhmijea@yahoo.com, violetavula@hotmail.com, ${ }^{*}$ teutapustina@hotmail.com, \\ apostolska@yahoo.com, ktringa@hotmail.com, lindihanaemini@hotmail.com
}

Received 30 December 2014; accepted 25 February 2015; published 2 March 2015

Copyright (C) 2015 by authors and Scientific Research Publishing Inc.

This work is licensed under the Creative Commons Attribution International License (CC BY).

http://creativecommons.org/licenses/by/4.0/

(c) (i) Open Access

\begin{abstract}
The maxillary second molar contains three roots and three canals. Variations of the maxillary second molar are reported in numerous studies in vitro and in vivo. Dentists are required to have adequate knowledge related to root canal morphology and their possible variations. The aim of this study was to present a case report about a diagnosis and treatment in maxillary second molar with single root and single canal. It is concluded that the diagnosing of these unusual cases is of high importance for successful endodontic treatment of these teeth.
\end{abstract}

\section{Keywords}

Maxillary Second Molar, Single Root, Single Canal Morphology

\section{Introduction}

Successful endodontic treatment of teeth requires knowledge related to root canal morphology. Maxillary second molar is similar to maxillary first molar, which is smaller in all parameters. Maxillary second molar usually has three root canals of which two are on the buccal side and correspond with its roots, and palatinal canal which

\footnotetext{
*Corresponding author.
}

How to cite this paper: Ajeti, N., Vula, V., Apostolska, S., Pustina, T., Kelmendi, T., Emini, L., Mrasori, S. and Ademi, R. (2015) Maxillary Second Molar with Single Root and Single Canal-Case Report. Open Journal of Stomatology, 5, 47-52. 
also corresponds with this root [1].

Cases of maxillary second molar with two palatal roots [2], four roots [3], three bucal roots [4] and five roots [5] have been previously reported in literature. Variations have also been reported in the form of fewer or lesser number of canal [6].

These roots have internal anatomic variations and might usually have a C-shaped canal configuration [7].

Fava et al. [6] reported a single root and a single canal on the maxillary and mandible second molar. This feature is more often on lower mandible molars, but it can also appear on maxillary molars, other molars and premolars. Therefore, the majority of studies related to variations of maxillary molars are related to first molar since variations of maxillary second molar are rare.

There are various methods applied to describe complicated configuration of teeth root such as: longitudinal and transversal teeth projection, the system of root canal traces with resin and silicon, the technique of irrigation of canal by injecting hematociclyne and india ink color, in vivo and ex vivo research, radiographic assessment, application of electronic microscope, application of operative microscope and a loop, computer three-dimensional reconstruction and micro-computerized tomography [8].

The aim of this clinical case presentation was to describe the unusual anatomic area of maxillary second molar.

\section{Case Report}

A 25-year-old female patient visited the Department of Conservative Dentistry and Endodontic in University Dental Clinical Center of Prishtina, Kosovo. Clinical examination revealed occlusal composite restoration. Her primary complain, was spontaneous pain on the left maxillary second molar. The tooth was sensitive in vertical percussion, coldness and warmness. Pain appeared more frequently during the night lasting 2 to 3 hours with brief calming periods. The clinical examination was associated with radiographic (Sirona Siemens, Germany) and orthopamographic imaging (Owandy, France).

As mentioned, in the radiographic and orthopantomographic (OPG) image of both maxillary second molars was observed an unusual morphology. Both maxillary molars had only one root with a single apex and a single wide canal localized in the central part of the root, (anatomic classification according to Fan) [9], compared to mandible second molars, which had a normal root and canal morphology (two roots, three canals) (Figure 1 and Figure 2).

After plexus anesthesia Articaine HCl. 4\% with Epinephrine 1:100,000 Injection (Septocaine, Septodont, France), the cavity was opened. After removal of the restoration the trepanation was done. Working length was determined by Apex locator (Dentaport, Morita, Japan). Root canals were cleaned and shaped using K-Files (K-Reamers, Edenta le, Swiss) with conventional method. After each instrumentation the canal was irrigated with $2.5 \% \mathrm{NaOCl}$ solution (Sodium Hypochlorite Solution, Sigma Aldrich-Germany). The inorganic component was removed with EDTA (Ethyilendiamine tetra acetic, acid disodium salt dehydrates, Czech Republic) solution with $17 \%$ concentration and final irrigation was done with a physiological solution $\mathrm{NaCl} 0.9 \%$ (B-Braun, Germany). After tooth canal instrumentation the root was dried with a sterile paper point. The gutta-percha (Dia Dent, Korea) was placed with a temporary filling to conduct a test image (Figure 3).

After the imaging the teeth root canal was obturated with cold lateral guttapercha with Canason (Vocco, Germany) and a lateral condensation of gutta-percha. To verify the filling, the patient's tooth was imaged again (Figure 4).

\section{Discussion}

The variation of maxillary second molar with single root and single canal is easily to detect in routine radiographs, as in this case. The use of multi angled diagnostic radiographs may be very useful on diagnosis of typical cases. However, care should be taken to assess the correct anatomy on the preoperative radiograph. In this way, we can reduce confusion with another anatomic variation of the same tooth where two roots are present (bucal and palatal), that could be superimposed on the diagnostic radiograph.

Conventional intraoral periapical radiographs are in important diagnostic tool in endodontics for assessing the root morphology and canal configuration. [10] Recently newer diagnostic methods such as computed tomography (CT) and spiral computed tomography (SCT) overcome the disadvantages of radiographs by producing a these dimensional image. These imaging techniques have emerged as powerful tools for evaluation of root canal tomography [11]. 


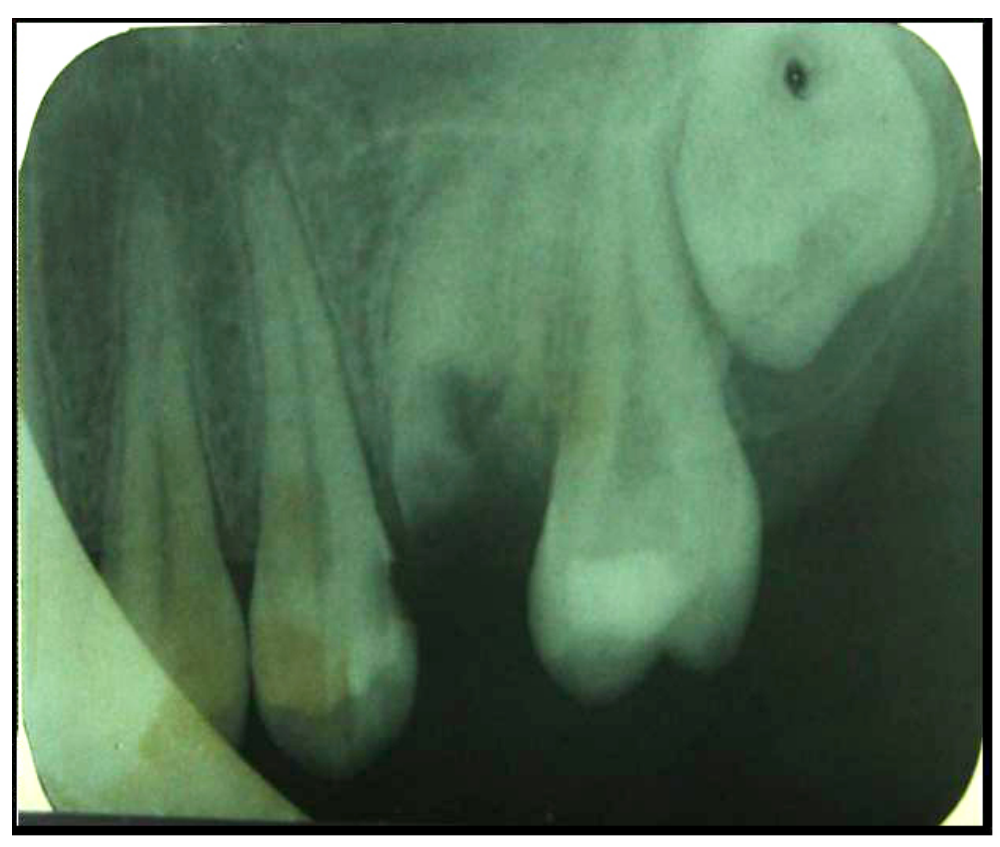

Figure 1. Maxillary second molar of the right side with a single root and a single canal.

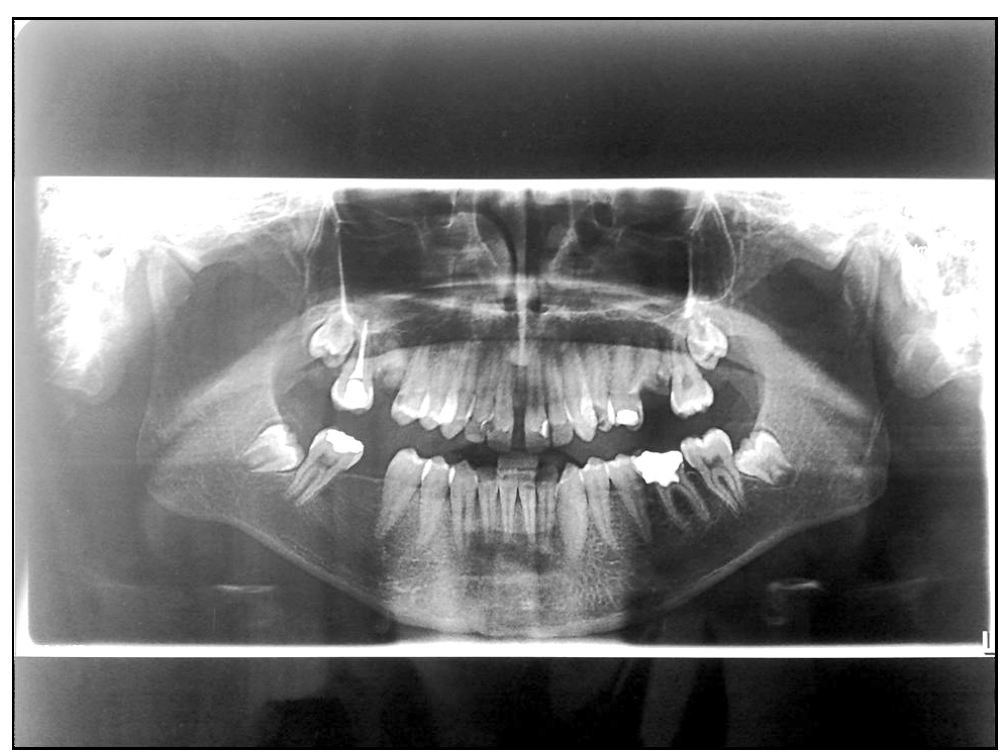

Figure 2. Ortopantomogram [OPG].

During the discussion of this presentation, there are two important aspects to consider. Firstly, there is the presence of an unusual morphology in the maxillary second molar and secondly there is a morphological change in both maxillary sides. Our research partially corresponds with Fava et al., [6] since he has encountered four second molars of both upper and lower jaws with single root and single canal, compared to our study where this feature was found only on maxillary second molars.

In endodontic literature more is written about maxillary second molars with triple roots and triple canals compared to maxillary second molar that could have a single root and a single canal [12] [13]. Variations of the maxillary second molars are reported in numerous studies in vitro and in vivo.

Hartwell \& Bellizi [14] concluded that the maxillary second molar with a single root and a single canal is present in $0.6 \%$ of cases. Peikoff et al. [15] in their retrospective study included 520 treated teeth in endodontic 


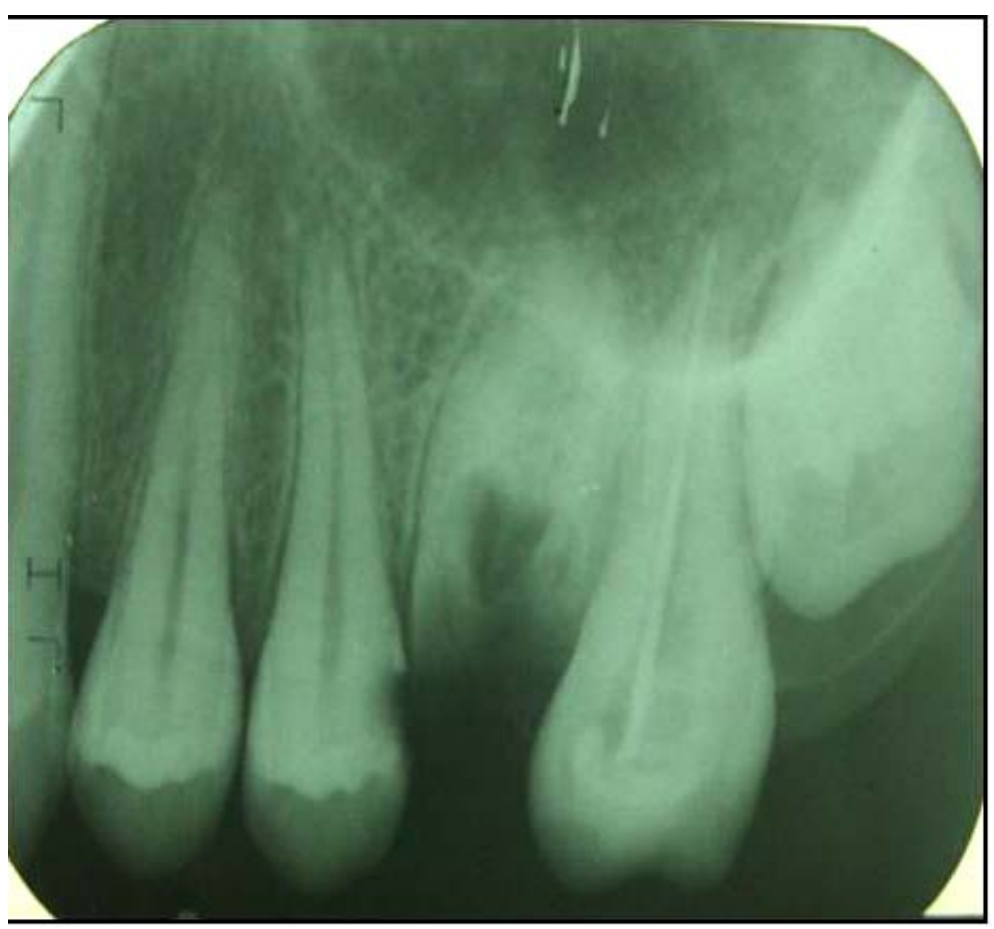

Figure 3. Right maxillary second molar-test image with gutta-percha.

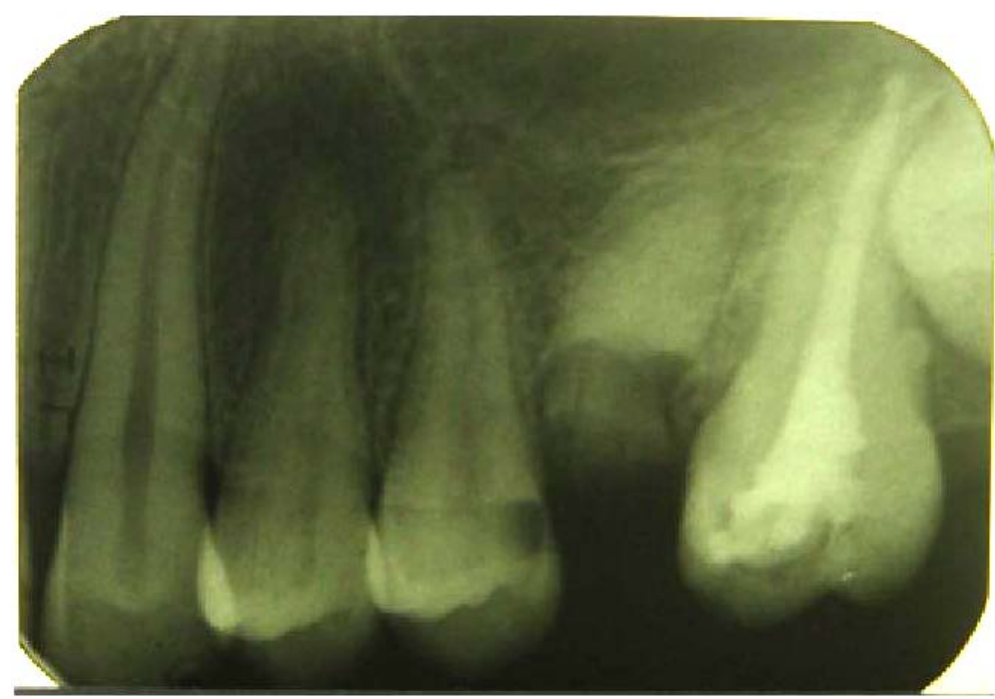

Figure 4. Maxillary second molar with final filling.

way, primarily maxillary second molars. Based on their radiographic study they found that $3.1 \%$ of these teeth had a single root and a single canal. In their research Carlsen et al. [16] included 104 teeth with single root, primarily maxillary second molars. They did cut teeth in the cement-enamel junction, in the middle of the root and another cut in the apical part of tooth. Their study of teeth cut in the middle of the root concluded with $25.96 \%$ of cases of examined teeth had a single canal found on the central part of the root. Their study was conducted using stereo-microscope.

Libfeld and Rotstein [3] reported of the incidence of maxillary second molar with single root and single canal in their in vivo study. They assessed 200 radiographies of patients treated in an endodontic way and reported that this feature was evident in $0.5 \%$ of cases. Similar results were also found by Rwenyonyi et al. [17] but in fused roots of maxillary second molar. On the other hand, according to Hua XI et al. [18] the incidence of maxillary 
second molar with single root and single canal is very rare. YL Ng [19] and Alavi [2002] [20] failed to find a case in their 77 maxillary second molar with a presence of a single root and a single canal. These teeth variations can be easily detected via radiography. However, one should be careful of the superimposition of root and the image gained by radiography. If in daily practice an unusual anatomic image is found, it is preferred that the same image is done in the other side of the jaw. Also according to Fava and Dummer, when aiming to obtain additional information there should be conducted radiography of tooth in mesial-distal direction. From a clinical staind point when the initial radiograph shows the image of unusual anatomic it is recommended to take a radiograph of the contralateral tooth [21]. Yang et al. in their study reported that maxillary second molars had fused roots in $40.1 \%$ [22]. Fused roots or incompletely separated roots are common in the maxillary second molars amongst Chinese people, while C-shaped roots and root canals in maxillary molars are not frequently seen. In another study, in Chinese population the incidence of single root in the maxillary second molar has been found in $10 \%$ with CBCT [23].

Kim et al. in Korean population, found that the incidence of fused roots was $0.73 \%$ in the first molars and $10.7 \%$ in second molars withy cone beam computed tomography [24].

In endodontic practice variations of root and canals of molars in the same side of jaws can be found as well. Bernatti et al. [25] in their study included 97 teeth of maxilla and mandible. They studied the connection in counter-lateral pairs of unusual anatomic presence. They also described the presence of fused roots in maxillary second molar and mandible. Through radiography they found the presence of maxillary second molar with a single root and a single canal, and a similar feature in the other side of the jaw. They concluded that teeth of the same group, in both sides of the jaw, with the same patient, have a similar anatomic morphology which also found in our study.

Although the incidence of single root and single canal is not high. For this reason, it is important to take these variations into consideration during root canal treatment of maxillary molar in order to ensure success. On the other hand these teeth have good endodontic prognosis, because of wide and accessible canal.

\section{Conclusion}

Anatomic variations such as: fusion, germination or anomalies of tooth root can often be diagnosed by radiography. Therefore, the usage of various angulations during radiographic imaging assists us in revealing these unusual cases in tooth root and canal. The use of CBCT provides new capabilities for assessment of the morphology and root anatomy of molar teeth. CBCT must be used in those cases where the conventional radiographic examination is not conclusive concerning the presence or absence of a supernumerary root. Even though the occurrence of maxillary second molar with a single root and a single canal is not high, diagnosing these unusual cases is of tremendous importance for successful endodontic treatment of these teeth.

\section{References}

[1] Pecora, J.D., Woefel, J.B., Neto, M.D. and Issa, E.P. (1992) Morphologic Study of the Maxillary Molars, Part II International Anatomy. Brazilian Dental Journal, 3, 53-57.

[2] Deveaux, E. (1999) Maxillary Second Molar with Two Palatal Roots. Journal of Endodontics, 25, 571-573.

[3] Liebfield, H. and Rotstein, I. (1989) Incidence of Four-Rooted Second Molars: Literature Review and Radiographic Survey of 1,200 Teeth. Journal of Endodontics, 15, 129-131.

[4] Fahid, A. and Taintor, J.F. (1988) Maxillary Second Molar with Tree Buccal Roots. Journal of Endodontics, 14, 181183. http://dx.doi.org/10.1016/S0099-2399(88)80261-9

[5] Kottoor, J., Hemmamalathi, S., Sudha, R. and Velnurugan, N. (2000) Maxillary Second Molar with 5 Roots and 5 Canals Evaluated Using Cone Beam Computerized Tomography: A Case Report. Oral Surgery, Oral Medicine, Oral Pathology, Oral Radiology, and Endodontology, 109, e162-e165.

[6] Fava, L.R.G., Wienfeld, I., Fabri, F.P. and Pais, C.R. (2000) Four Second Molars with Single Root and Single Canals in the Same Patient. International Endodontic Journal, 33, 138-142. http://dx.doi.org/10.1046/j.1365-2591.2000.00272.x

[7] Shetty, N., Singh, V. and Rijal, S. (2009) Single Rooted Mandibular Second Molars with Single Canal: Rare Occurance. Endodontology, 21, 53-57.

[8] Ionndis, K., Lumbrianidis, T., Beltes, P., Besi, E. and Milliari, M. (2011) Endodontic Management and Cone-beam Computed Tomography Evaluation of Seven Maxillary and Mandibular Molar with Single Roots and Single Canals in 
a Pattient. Journal of Endodontics, 37, 103-109. http://dx.doi.org/10.1016/j.joen.2010.09.001

[9] Fan, B., Cheung, G.S., Fan, M., Gutmann, J.I. and Biam, Z. (2004) C-Shaped Canal System in Mandibular Second Molars. Part I, Anatomical Features. Journal of Endodontics, 30, 899-903.

[10] Hildebolt, C.F., Vannier, M.W., Pilgram, T.K. and Shtrout, M.K. (1990) Quantitative Evaluation of Digital Dental Radiograph Imaging Systems. Oral Surgery, Oral Medicine, Oral Pathology, 70, 661-668. http://dx.doi.org/10.1016/0030-4220(90)90419-S

[11] Peters, O.A. (2004) Current Challenge and Concept in the Preparation of Root Canal Systems: A Review. Journal of Endodontics, 30, 559-567. http://dx.doi.org/10.1097/01.DON.0000129039.59003.9D

[12] Ingle, J.I., Bakland, L.K., Peters, D.L., Burchans, S. and Mullaney, T.P. (1994) Endodontic Cavity Preparations. 4th Edition, Baltimore, 92, 227.

[13] Walton, R.E. and Vertucci, F.J. (1996) Internal Anatomy. In: Walton, R.E. and Torabinejad, M., Eds., Principles and Practice of Endodontics, 2nd Edition, WB Saunders, Philadelphia.

[14] Hartwell, G. and Bellizi, R. (1982) Clinical Investigation of in Vivo Endodontically Treated Mandibular and Maxillary Molars. Journal of Endodontics, 8, 555-557. http://dx.doi.org/10.1016/S0099-2399(82)80016-2

[15] Peikoff, M.D., Christie, W.H. and Fogel, H.M. (1996) The Maxillary Second Molar: Variations in the Number of Root and Canals. International Endodontic Journal, 29, 365-369. http://dx.doi.org/10.1111/j.1365-2591.1996.tb01399.x

[16] Carlsen, O., Alexandersen, V., Heilmant, T. and Jacobson, P. (1992) Root Canals in One-Rooted Maxillary Second Molars. Scandinavian Journal of Dental Research, 100, 249-256.

[17] Rwenyonyi, C.M., Kutesa, A.M., Muvazi, L.M. and Buwembo, W. (2007) Root and Canal Morphology of Maxillary First and Second Molar Teeth in Ugandan Population. International Endodontic Journal, 40, 679-683. http://dx.doi.org/10.1111/j.1365-2591.2007.01265.x

[18] Wang, Y., Hui, X. and Huang, D.M. (2011) Maxillary and Second Molar with Curved Single Root and Single Canal: A Case Report. Hua Xi Kou Qiang Yi Xue Za Zhi, 29, 104-105.

[19] Ng, Y.L., Aung, T.H., Alavi, A. and Gulabivala, K. (2001) Root and Canal Morphology of Burmese Maxillary Molars. International Endodontic Journal, 34, 620-630. http://dx.doi.org/10.1046/j.1365-2591.2001.00438.X

[20] Alavi, A.M., Opasanon, A., Ng, Y.L. and Gulabivala, K. (2002) Root and Canal Morphology of Thai Maxillary Molars. International Endodontic Journal, 35, 478-485. http://dx.doi.org/10.1046/j.1365-2591.2002.00511.X

[21] Fava, L.R. and Dummer, P.M. (1997) Periapical Radiographic Techniques during Endodontic Diagnosis and Treatment. International Endodontic Journal, 30, 250-261.

[22] Yang, Z.P., Yang, S.F. and Lee, G. (1998) The Root and Root Canal Anatomy of Maxillary Molars in a Chinese Population. Dental Traumatology, 4, 215-218. http://dx.doi.org/10.1111/j.1600-9657.1988.tb00324.X

[23] Zhang, R., Yang, H., Yu, X., Wang, H., Hu, T. and Dummer, P.M. (2011) Use of CBCT to Identify the Morphology of Maxillary Permanent Molar Teeth in a Chinese Subpopulation. International Endodontic Journal, 44, 162-169.

[24] Kim, Y., Lee, S.J. and Woo, J. (2012) Morphology of Maxillary First and Second Molars Analyzed by Cone-Beam Computed Tomography in a Korean Population: Variations in the Number of Roots and Canals and Their Incidence of Fusion. Journal of Endodontics, 38, 1063-1068. http://dx.doi.org/10.1016/j.joen.2012.04.025

[25] Bernatti, O., Valdrighi, L. and Benatti, M.A. (1994) Aspectos anatomicôs da cavidade pulpar. Revista Gaúcha de Odontologia, 42, 111-115. 